\title{
Seabed images versus corer sampling: a comparison of two quantitative approaches for the analysis of marine benthic communities in the southern Weddell Sea (Southern Ocean)
}

\author{
Santiago E. A. Pineda-Metz ${ }^{1} \cdot$ Dieter Gerdes $^{1}$
}

Received: 5 April 2017 / Revised: 18 August 2017 / Accepted: 9 October 2017 / Published online: 22 October 2017

(C) The Author(s) 2017. This article is an open access publication

\begin{abstract}
Corer sampling and seabed imaging are two quantitative approaches used to investigate benthic fauna. Despite the complementary nature of these methods, very few studies have been done using both in parallel. Here, we compare benthic composition and abundance data derived from the quantitative faunistic analysis of both multibox corer samples (MBC) and seabed images (SBI) taken concomitantly at 16 stations in the Filchner-Ronne region of the southern Weddell Sea (Southern Ocean) during R/V Polarstern cruise PS82 (ANT-XXIX/9) in 2013/14. A total of 43 benthic taxa were found, 34 in MBC and 29 in SBI samples. Mean benthic abundance derived from MBC was 20 times higher than the SBI abundance (1708 vs. 71 ind $\mathrm{m}^{-2}$ )—best explained by SBI being a method focusing on the epifauna alone, whereas MBC also captures the more abundant infauna. Differences in taxa caught by both gears demonstrated that MBC alone were not sufficient for a comprehensive representation of the entire benthic fauna. The among-station similarity patterns derived from both methods correlated significantly; a different combination of taxa best explained the specific distribution patterns. Overall, our results demonstrate similar and comparable spatial distribution patterns in the benthic communities by both methods. We therefore highly recommend the use of both, $\mathrm{MBC}$ and SBI in combination.
\end{abstract}

Keywords Infaunal- and epifaunal benthos $\cdot$ Filchner region · Zoobenthic distribution patterns - Quantitative sampling

Santiago E. A. Pineda-Metz

santiago.pineda.metz@awi.de

1 Alfred-Wegener-Institut Helmholtz-Zentrum für Polar- und Meeresforschung, D-27568 Bremerhaven, Germany

\section{Introduction}

In general, benthic marine macrofauna can be divided into three habitat-related compartments: (a) infauna living in the sediment; (b) epifauna comprising vagile and sessile organisms living on the sea floor, and (c) suprabenthic fauna living above the sea floor but remaining connected to the benthic habitat (Dauvin and Vallet 2006).

Specific collection gear has been designed to adequately sample each of these benthic compartments. While trawled gear provides qualitative estimates of species' numbers and richness (Clark et al. 2016), corers are used to quantitatively determine abundance and biomass of the different benthic taxa by providing precise numeric data that allow for inferences on the general ecology of Antarctic benthos. However, quantitative abundance data for Southern Ocean macroinvertebrates are still comparatively scarce (Clarke 2008). In the present study, we compare the performance of two sampling gears by assessing the quantitative data obtained by (a) multibox corer samples and (b) seabed images.

Corers have been extensively used in marine ecology and are mainly used for sampling soft-bottom benthic fauna across multiple size ranges. One commonly used corer is the giant box corer, which covers a seabed area of $0.25 \mathrm{~m}^{2}$ (AWI 2006) and can catch organisms $>20 \mathrm{~mm}$. Another example of coring device is the multibox corer (MBC; Gerdes 1990). While single corers provide information of large macrobenthos, they are inefficient as many deployments are required to build up a statistically robust picture of the nature of macrobenthic distribution patterns. In comparison, each box of a $\mathrm{MBC}$ is inefficient to sample large macrobenthos (each box covers an area of $0.024 \mathrm{~m}^{2}$ ). However, the circular area subsampled per deployment of a MBC is $\sim 2.3 \mathrm{~m}^{2}$, this allows to "better" represent patchily distributed macrobenthos, while 
being able to treat each of the 9 cores as a replicate (Gerdes 1990).

Corers often provide relatively undisturbed samples of both infaunal- and epifaunal benthos, although they are better suited to study the infaunal compartment (Eleftheriou and McIntyre 2005; Lozach et al. 2011). The problems of sampling epifaunal benthos with corers are (a) the scattered abundance of large epifauna (e.g., hexactinellid sponges); (b) patchily distributed organisms (e.g., ophiuroids; Syvitski et al. 1989) are underestimated; (c) motile organisms tend to avoid being caught by corers (e.g., Thurston et al. 1994); and (d) the approaching gear may generate a bow-wave effect that flushes away smaller organisms. For further discussion about corers and other soft-bottom sampling gear, we refer to Blomqvist (1991) or Eleftheriou and McIntyre (2005), and further literature cited therein.

The disadvantages of corers for the investigation of epifaunal benthos have led to the implementation of seabed imaging methods to overcome these constraints (Rumohr 1995; Solan et al. 2003). Since its first use over a century ago in the 1890s, seabed imaging transformed from a qualitative technique to a quantitative one and has been recognized as a valuable complement to traditional benthos sampling approaches involving trawls or corers. A wide range of information can be obtained from seabed images, as they provide an in situ view of epibenthic habitats and communities. If spatially calibrated with scales (e.g., by laser pointers), and corrected for optical distortion, quantitative data on epifaunal benthic abundance and, to some extent, biomass estimations can be derived by this approach (Rumohr 1995). However, there are some constraints limiting the use of seabed images (Rumohr 1995): (a) the light backscattering under turbid conditions can result in poor image quality; (b) highly mobile, cryptic, and small-sized organisms are not well recorded; and (c) high costs for acquisition and maintenance of seabed imaging equipment may be prohibitive.

In the Weddell Sea and off the Antarctic Peninsula, benthic communities have been studied by means of both corers (e.g., Gerdes et al. 1992, 2003, 2008; Sañé et al. 2012) and seabed imaging (e.g., Gutt and Piepenburg 2003; Gutt et al. 2011, 2013; Fillinger et al. 2013). Despite the fact that these methods complement each other, studies using both approaches in a comparative manner are scarce. This scarcity of information leaves open questions such as (a) how different are the infaunal- and epifaunal benthos sampled by both gears in parallel? or (b) are benthic distribution patterns resulting from quantitative corer sampling and obtained from a parallel seabed imaging survey correlated? Piepenburg et al. (2002) conducted such a study off King George Island, using a combination of multibox corer (Gerdes 1990) and a still camera system (Piepenburg and Juterzenka 1994) to comparatively analyze the spatial distribution of infaunaland epifaunal benthos with a special focus on assemblage description. In our study, we aim to make a comprehensive comparison between both MBC and SBI to illustrate the differences in results obtained by these methodologies. Furthermore, we analyzed the resemblance of the distribution patterns of infaunal- and epifaunal benthos.

\section{Materials and methods}

Fieldwork was performed during the R/V Polarstern PS82 (ANT-XXIX/9) expedition in the Weddell Sea from December 2013 to March 2014 (Knust and Schröder 2014). A total of 16 stations were investigated with a MBC (Table 1). The stations were distributed across three sub-regions of the Filchner-Ronne Outflow System (FROS): (a) the eastern and (b) western flanks of the Filchner Trough, and (c) the trough itself (Fig. 1).

The MBC used to sample infaunal benthos covers a circular area of $\sim 2.3 \mathrm{~m}^{2}$ and provides a maximum of 9 cores, each core covering $0.024 \mathrm{~m}^{2}$. Prior to core sampling, seabed images were taken with an underwater camera (Canon EOS D100) installed in a pressure housing attached to the MBC. Images were taken every $15 \mathrm{~s}$ for 15 min resulting in a mean of 55 images per deployment. The high-definition photographs were taken from 1 to $2 \mathrm{~m}$ above the seabed.

Sediment cores obtained with the MBC were sieved on deck over a 500- $\mu \mathrm{m}$ mesh size sieve. The sieve residues were stored in 5-L containers and fixed in a 5\% sea waterformaldehyde solution buffered with borax. Overall, 101 corer samples were taken at 16 stations. These samples represented an average of $0.15 \mathrm{~m}^{2}$ seabed per station. Benthic organisms were sorted from these samples, identified to the lowest possible taxon via a stereomicroscope and classified into 34 major taxonomic groups (Table 2). Abundance values (ind $\mathrm{m}^{-2}$ ) were determined for each taxon and station. For colonial (e.g., bryozoans and hydrozoans) and large macrobenthic organisms (e.g., glass sponges), only presence was recorded.

A total of 279 seabed images (SBI) obtained at the 16 stations were analyzed. At three stations (033, 040, and 206), all images obtained were analyzed in order to calculate the number of images per station sufficient to cover all taxonomic groups differentiated. The taxon accumulation curves at these three stations clearly indicated that the analysis of 15 images is sufficient for this purpose. For this reason, at all other stations, a randomly selected image subset of 15 SBI was used for the description of the epifaunal community. The average seabed area analyzed per SBI station was $14.6 \mathrm{~m}^{2}$, and an overall seabed area of $233.2 \mathrm{~m}^{2}$ was investigated at the 16 stations considered in this study.

The optical axis of the camera attached to the MBC had an inclination of $45^{\circ}$ in relation to the seabed. To compensate for the distortion of the area pictured, the images were 
Table 1 Benthic stations investigated during RV Polarstern cruise PS82 (ANT-XXIX/9) 2013/14. Data on fine (clay and silt) and coarse (gravel and sand) sediments from Diekmann and Kuhn (1999a)

\begin{tabular}{llllllll}
\hline PS82 st. no. & Latitude $(\mathrm{S})$ & Longitude $(\mathrm{W})$ & Water depth $(\mathrm{m})$ & Sub-region & $\begin{array}{l}\text { Coarse sedi- } \\
\text { ment }(\%)\end{array}$ & $\begin{array}{l}\text { Fine sedi- } \\
\text { ment }(\%)\end{array}$ & $\begin{array}{l}\text { Sea water } \\
\text { density }(\text { sigma- } \\
\text { theta) }\end{array}$ \\
\hline 033 & & & & & Filchner Trough & 55.95 & 44.05 \\
040 & $75^{\circ} 56.83^{\prime}$ & $31^{\circ} 40.57^{\prime}$ & 684 & Eastern flank & 77.82 & 22.18 & 27.92 \\
066 & $76^{\circ} 03.96^{\prime}$ & $30^{\circ} 16.83^{\prime}$ & 472 & Filchner Trough & 34.34 & 65.66 & 27.93 \\
089 & $77^{\circ} 06.09^{\prime}$ & $36^{\circ} 34.39^{\prime}$ & 1111 & Eastern flank & 66.18 & 33.82 & 27.69 \\
098 & $76^{\circ} 59.02^{\prime}$ & $32^{\circ} 51.05^{\prime}$ & 254 & Filchner Trough & 58.76 & 41.24 & 27.89 \\
116 & $77^{\circ} 42.76^{\prime}$ & $35^{\circ} 55.73^{\prime}$ & 585 & Filchner Trough & 28.69 & 71.31 & 27.90 \\
125 & $77^{\circ} 36.77^{\prime}$ & $38^{\circ} 56.70^{\prime}$ & 1060 & Eastern flank & 86.94 & 13.06 & 27.69 \\
154 & $75^{\circ} 29.48^{\prime}$ & $27^{\circ} 24.60^{\prime}$ & 286 & Eastern flank & 20.78 & 79.22 & 27.78 \\
163 & $74^{\circ} 36.53^{\prime}$ & $28^{\circ} 28.72^{\prime}$ & 1217 & Eastern flank & 27.22 & 72.78 & 27.76 \\
164 & $74^{\circ} 39.94^{\prime}$ & $28^{\circ} 40.16^{\prime}$ & 696 & Eastern flank & 60.63 & 39.37 & 27.68 \\
200 & $74^{\circ} 53.67^{\prime}$ & $26^{\circ} 42.48^{\prime}$ & 290 & Western flank & 85.43 & 14.57 & 27.83 \\
206 & $74^{\circ} 34.73^{\prime}$ & $36^{\circ} 23.70^{\prime}$ & 426 & Western flank & 83.78 & 16.22 & 27.88 \\
226 & $74^{\circ} 26.09^{\prime}$ & $35^{\circ} 43.48^{\prime}$ & 1140 & Western flank & 84.29 & 15.71 & 27.82 \\
236 & $74^{\circ} 21.12^{\prime}$ & $37^{\circ} 36.14^{\prime}$ & 554 & Western flank & 83.87 & 16.13 & 27.84 \\
242 & $74^{\circ} 13.23^{\prime}$ & $37^{\circ} 39.67^{\prime}$ & 798 & Western flank & 65.39 & 34.61 & 27.82 \\
325 & $74^{\circ} 40.84^{\prime}$ & $39^{\circ} 04.03^{\prime}$ & 436 & Eastern flank & 46.04 & 53.96 & 27.75 \\
\hline
\end{tabular}

Near-bottom water densities $\left(\mathrm{kg} \mathrm{m}^{-3}\right)$ from Schröder and Wisotzki (2014)

edited prior to analysis with the Camera Distortion Correction tool of the software Adobe Elements v5.0. The size of the seabed area in each image, determined by means of two laser-pointer dots with a distance of $4.5 \mathrm{~cm}$ from each other, ranged from 0.38 to $2.86 \mathrm{~m}^{2}$, depending on the distance of the camera from the seafloor. In the laboratory, all organisms visible in the SBIs were counted, identified to the lowest possible taxon, and classified into 29 taxonomic groups (Table 2). Organism counts were standardized to abundance figures (ind $\mathrm{m}^{-2}$ ). The abundance of colonial organisms was calculated as area $\left(\right.$ in $^{2}$ ) covered by the colonies. To make results and units between SBI and MBC data comparable, these abundance values were not used for statistical analysis.

Multivariate statistics were applied to perform benthic community analyses of abundance data obtained from both MBC and SBI by means of the software package PRIMERv6 with its PERMANOVA+ add-on (Clarke and Gorley 2006; Anderson et al. 2008). A similarity matrix was calculated by means of Euclidean distances. This similarity matrix was used in a PERMANOVA analysis to test for interactions between sampling method and sampled stations. For the design of the PERMANOVA, the following two factors were considered (a) sampling gear (MBC and SBI) as a fixed factor, and (b) station (16 levels) as a random factor. The Monte Carlo option of the PERMANOVA routine was used to ensure 9999 permutations. In case of a significant interaction between the two factors, pairwise tests were performed to examine differences between methods and across stations. Abundance values per taxon and core/image were 4th-root transformed to reduce the effect of high variation among taxa. These transformed values were used in a twoway SIMPER test (Clarke and Warwick 1994) to establish the percent dissimilarity between MBC and SBI across stations, and which taxa were the primary contributors to these differences.

Mean abundance values for each MBC and SBI station were calculated. These data were arranged in two matrices featuring the mean abundances per taxon and station (excluding colonial organisms). Abundance figures were 4th-root transformed to reduce the effect of high variation among taxa. Between-station similarities were calculated using the Bray-Curtis Index (Bray and Curtis 1957). The resemblance pattern in the similarity matrices was visualized using 2-d multidimensional scaling (MDS) plots. The stations were grouped based on a cluster and SIMPROF analysis (Clarke and Gorley 2006). To recognize the taxa that primarily explain these station groups, principal component analyses (PCA) of the weighted variables were performed. MDS and PCA results were compared to evaluate differences between distribution patterns of the two benthic community fractions represented in the MBC and SBI data (infauna vs. epifauna).

A RELATE test (Clarke and Warwick 1994) was performed to test for a correlation between the two similarity matrices based on MBC and SBI data, to check the resemblances between infaunal and epifaunal distribution patterns. In case a significant correlation was observed with the RELATE test, BEST tests (Clarke and Gorley 2006) were 


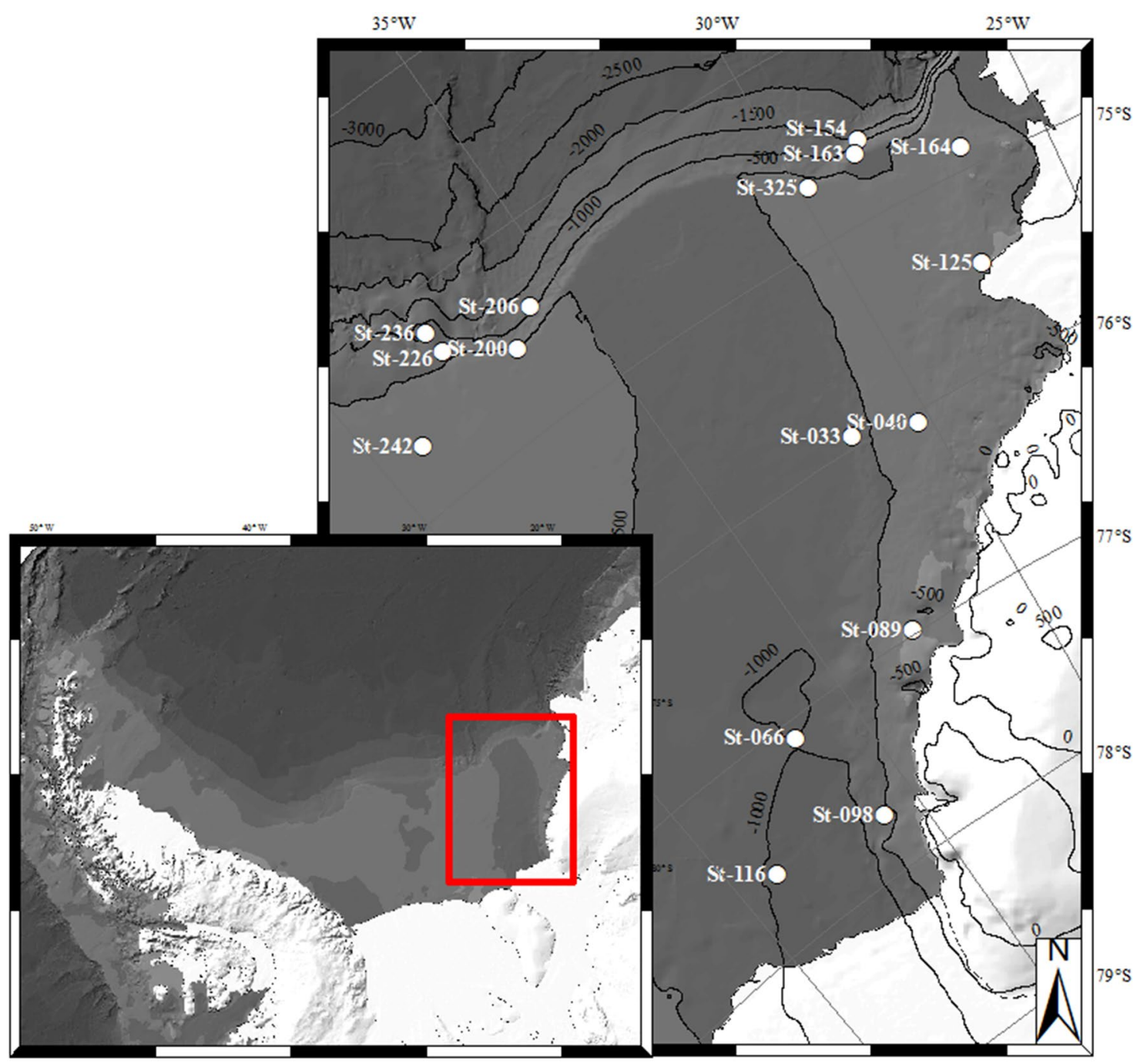

Fig. 1 Locations of benthos stations in the Filchner-Ronne Outflow System (FROS) region in the southern Weddell Sea visited during R/V Polarstern cruise PS82 (ANT-XXIX/9) 2013/14. Bathymetric data from IBCSO (Arndt et al. 2013)

performed as well. BEST tests, as RELATE and Mantel tests (Mantel 1967), correlate two similarity matrices. One matrix is considered as the "explained" or dependent matrix and the other as the "explanatory" or independent matrix. As such, the test examines the variables from the "explanatory" matrix one at a time, then pairs of variables, triplets, and so on (Clarke et al. 2008). The BEST procedure then selects the variables that "best explain" the pattern of the "explained" matrix.

\section{Results}

Combining all SBI and MBC data, a total of 43 benthic taxa were found (Table 2). Eight taxa were exclusively found in SBI (gorgonians, actinarians, scleractinians, nudibranchs, cephalopods, mysids, serolids, and decapods), and 13 taxa were exclusively found in MBC samples (sipunculids, flatworms, nemerteans, priapulids, solenogastres, clitellate worms, echiurids, cumaceans, harpacticoid copepods, cirripeds, tanaidaceans, and ostracods; Table 2).

The mean total benthic abundances of the MBC stations varied from 104 to 4543 ind $\mathrm{m}^{-2}$, with an overall mean of 1708 ind $\mathrm{m}^{-2}$ and an overall median of 1325 ind $\mathrm{m}^{-2}$. Dominant taxa (i.e., those that contributed at least $75 \%$ to the mean abundance at the stations) were polychaetes, amphipods, clitellate worms, ophiuroids, and bivalves (Figs. 2, 3). The mean total epibenthic abundances of the SBI stations ranged from 16 to $170 \mathrm{ind}^{-2}$, with an overall mean of 71 ind $\mathrm{m}^{-2}$ and an overall median of 64 ind $\mathrm{m}^{-2}$. Following the criteria given above, ophiuroids, holothurians, polychaetes, tunicates, and unidentified organisms were identified as dominant taxa in the SBI (Figs. 2, 4). 
Table 2 Occurrence of benthic taxa in seabed images ( $\mathrm{x}$ ) and multibox corer samples (o) collected at 16 stations during RV Polarstern cruise PS82 (ANT-XXIX/9) 2013/14

\begin{tabular}{|c|c|c|c|c|c|c|c|c|c|c|c|c|c|c|c|c|}
\hline TAXA/Stations & 033 & 040 & 066 & 089 & 098 & 116 & 125 & 154 & 163 & 164 & 200 & 206 & 226 & 236 & 242 & 325 \\
\hline Porifera & $\mathrm{x}$ & o & & xo & o & o & xo & xo & xo & xo & o & xo & xo & xo & $\mathrm{x}$ & xo \\
\hline Stauromedusae & & & & & & & & & & $\mathrm{x}$ & & & & & & \\
\hline Hydrozoa & & o & & ox & & o & $\mathrm{x}$ & $\mathrm{x}$ & xo & xo & xo & xo & xo & $\mathrm{x}$ & o & xo \\
\hline Alcyonacea & & & & $\mathrm{x}$ & $\mathrm{x}$ & & $\mathrm{x}$ & $\mathrm{x}$ & $\mathrm{x}$ & $\mathrm{x}$ & $\mathrm{x}$ & $\mathrm{x}$ & $\mathrm{x}$ & $\mathrm{x}$ & $\mathrm{x}$ & $\mathrm{x}$ \\
\hline Actinaria & & & $\mathrm{x}$ & $\mathrm{x}$ & & $\mathrm{x}$ & $\mathrm{x}$ & $\mathrm{x}$ & $\mathrm{x}$ & $\mathrm{x}$ & $\mathrm{x}$ & & $\mathrm{x}$ & & & $\mathrm{x}$ \\
\hline Scleractinia & & & & & & $\mathrm{x}$ & & & $\mathrm{x}$ & $\mathrm{x}$ & & & & & & $\mathrm{x}$ \\
\hline Anthozoa $^{\mathrm{a}}$ & & o & & o & o & & o & & o & o & o & o & o & o & o & o \\
\hline Bryozoa & & xo & & xo & & o & xo & xo & xo & xo & xo & xo & xo & xo & xo & xo \\
\hline Brachiopoda & & & & & & & & & & o & o & xo & o & o & & \\
\hline Sipuncula & & o & & o & o & & & o & o & o & & & & o & & o \\
\hline Platyhelminthes & & & o & o & & & & & & & & & & & & \\
\hline Nemertina & o & o & & o & o & & o & o & o & o & o & o & o & o & & o \\
\hline Priapulida & & o & & & & & & & & & & & & & & o \\
\hline Polyplacophora & & & & & & & & o & xo & & & & & & & \\
\hline Solenogastres & & & & o & o & & & o & o & o & o & & o & & & o \\
\hline Bivalvia & o & o & $\mathrm{o}$ & o & o & o & o & o & o & xo & o & o & o & o & o & o \\
\hline Nudibranchia & & & & & & & & & & & & $\mathrm{x}$ & & & & \\
\hline Gastropoda & o & o & & o & o & & xo & xo & o & o & xo & o & o & & & xo \\
\hline Scaphopoda & & o & & & & & o & & o & o & & & & & & \\
\hline Cephalopoda & & & & & & & & & & & $\mathrm{x}$ & & & & & $\mathrm{x}$ \\
\hline Polychaeta & xo & xo & xo & xo & xo & xo & xo & xo & xo & xo & xo & xo & xo & xo & xo & xo \\
\hline Clitellata & o & o & o & o & o & o & o & o & o & o & o & o & o & o & o & o \\
\hline Echiurida & & & & & & & & & & o & & & & & & \\
\hline Pantopoda & & xo & & xo & $\mathrm{x}$ & & $\mathrm{x}$ & xo & o & xo & xo & o & xo & $\mathrm{x}$ & $\mathrm{x}$ & xo \\
\hline Mysida & $\mathrm{x}$ & & & & $\mathrm{x}$ & & $\mathrm{x}$ & $\mathrm{x}$ & & $\mathrm{x}$ & & & $\mathrm{x}$ & $\mathrm{x}$ & $\mathrm{x}$ & $\mathrm{x}$ \\
\hline Amphipoda & $\mathrm{x}$ & xo & $\mathrm{x}$ & o & o & & o & xo & o & xo & xo & o & o & xo & xo & xo \\
\hline Cumacea & o & o & & o & & o & o & o & o & o & & o & & & o & o \\
\hline Harpacticoida & & o & & o & o & & o & & o & o & o & o & o & & & \\
\hline Cirripedia & & & & & & & & & & & o & & & & & \\
\hline Serolidae & $\mathrm{x}$ & $\mathrm{x}$ & $\mathrm{x}$ & & & $\mathrm{x}$ & & $\mathrm{x}$ & & & $\mathrm{x}$ & & & $\mathrm{x}$ & & $\mathrm{x}$ \\
\hline Isopoda & o & o & & o & o & $\mathrm{x}$ & o & & o & xo & o & o & o & o & o & o \\
\hline Tanaidacea & & o & & o & o & o & o & o & o & o & o & & o & & o & o \\
\hline Ostracoda & o & o & & & o & & o & o & & o & & o & & & o & \\
\hline Decapoda & $\mathrm{x}$ & $\mathrm{x}$ & & & & & $\mathrm{x}$ & $\mathrm{x}$ & & $\mathrm{x}$ & $\mathrm{x}$ & & & & $\mathrm{x}$ & $\mathrm{x}$ \\
\hline Crustacea $^{\mathrm{a}}$ & $\mathrm{x}$ & $\mathrm{x}$ & & & $\mathrm{x}$ & $\mathrm{x}$ & & $\mathrm{x}$ & o & $\mathrm{x}$ & xo & & o & $\mathrm{x}$ & $\mathrm{x}$ & $\mathrm{x}$ \\
\hline Echinoidea & $\mathrm{x}$ & $\mathrm{x}$ & $\mathrm{x}$ & xo & $\mathrm{x}$ & $\mathrm{x}$ & $\mathrm{x}$ & $\mathrm{x}$ & xo & $\mathrm{x}$ & xo & $\mathrm{x}$ & $\mathrm{x}$ & $\mathrm{x}$ & $\mathrm{x}$ & $\mathrm{x}$ \\
\hline Holothuroidea & $\mathrm{x}$ & $\mathrm{x}$ & $\mathrm{x}$ & xo & xo & $\mathrm{x}$ & xo & xo & xo & xo & $\mathrm{x}$ & $\mathrm{x}$ & $\mathrm{x}$ & $\mathrm{x}$ & $\mathrm{x}$ & xo \\
\hline Asteroidea & & & & xo & $\mathrm{x}$ & $\mathrm{x}$ & $\mathrm{x}$ & $\mathrm{x}$ & xo & $\mathrm{x}$ & xo & $\mathrm{x}$ & xo & $\mathrm{x}$ & & $\mathrm{x}$ \\
\hline Ophiuroidea & $\mathrm{x}$ & xo & $\mathrm{x}$ & xo & xo & xo & xo & xo & xo & xo & xo & xo & xo & xo & xo & xo \\
\hline Crinoidea & o & & $\mathrm{x}$ & xo & $\mathrm{x}$ & & $\mathrm{x}$ & xo & xo & xo & $\mathrm{x}$ & & $\mathrm{x}$ & $\mathrm{x}$ & $\mathrm{x}$ & $\mathrm{x}$ \\
\hline Hemichordata & & & & & & & xo & & xo & & & $\mathrm{x}$ & & & & \\
\hline Tunicata & $\mathrm{x}$ & o & $\mathrm{x}$ & $\mathrm{x}$ & & xo & xo & $\mathrm{x}$ & xo & xo & o & $\mathrm{x}$ & $\mathrm{x}$ & xo & xo & $\mathrm{x}$ \\
\hline Unidentified & xo & & xo & $\mathrm{x}$ & $\mathrm{x}$ & $\mathrm{x}$ & $\mathrm{x}$ & xo & $\mathrm{x}$ & $\mathrm{x}$ & $\mathrm{x}$ & $\mathrm{x}$ & $\mathrm{x}$ & $\mathrm{x}$ & $\mathrm{x}$ & $\mathrm{x}$ \\
\hline
\end{tabular}

${ }^{a}$ Unidentified
Two-way PERMANOVA analysis showed significant variability in the structure of the benthic assemblages (Table 3) both, between methods (MBC, SBI) and among stations. Furthermore, there was also a significant between-factor interaction (Table 3), indicating that the effect of the MBC and SBI was not the same across all stations. Pairwise comparisons showed, however, significant differences between MBC and SBI at each station, albeit to a different degree ( $p$ values ranged from $<0.01$ to 0.03 ). A complimentary SIMPER test established $80.1 \%$ 

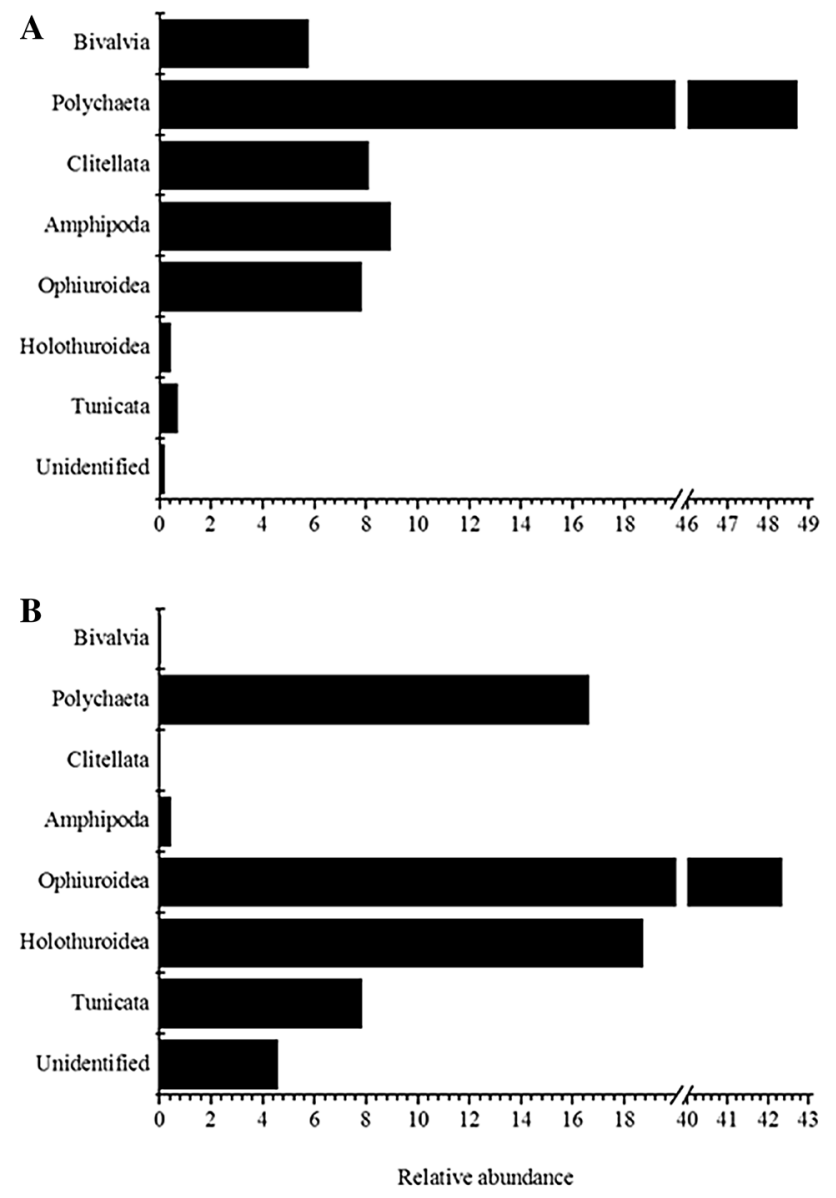

Fig. 2 Relative abundances (\%) of dominant benthic taxa identified in a multibox corer samples and $\mathbf{b}$ seabed images collected during R/V Polarstern cruise PS82 (ANT-XXIX/9) 2013/14

dissimilarity between MBC and SBI abundance values across all stations. The taxa that contributed $\sim 50 \%$ to this difference were polychaetes, ophiuroids, bivalves, amphipods, holothurians, and clitellate worms (Table 4).

Cluster and SIMPROF analysis distinguished five groups of MBC stations, and three groups of SBI stations (Fig. 5). A PCA of the weighted variables showed that the grouping of MBC stations was caused almost exclusively by polychaetes, and the SBI station grouping to be mainly affected by the abundances of ophiuroids and holothurians (Table 5; Figs. 6, 7).

MBC stations were divided into five groups (Fig. 5). Both MBC groups "a" and " $b$ " were composed of just one single station situated in the Filchner Trough at 684 (st. 033) and 1111 m depth (st. 066). MBC group "c" was composed of two stations located in the shallow area of the western flank of the trough (st. 242, $436 \mathrm{~m}$ depth), and the deep trough (st. $116,1060 \mathrm{~m}$ depth). MBC group "d" was also composed of two stations, both located on the western flank of the trough between 798 (st. 236) and $1140 \mathrm{~m}$ water depth (st. 206). MBC group "e" was the largest group with 10 stations, distributed across the entire FROS in a wide depth range (254-1217 m depth). In terms of abundance, all MBC groups were dominated by polychaetes. However, the second dominant taxon varied across station groups. For groups "a," "b," and "c," bivalves followed polychaetes, in group "a" they were almost as abundant as polychaetes, in groups " $b$ " and "c" clearly less abundant (Fig. 3). The second dominant taxon in group "d" was ophiuroids and in group "e," amphipods (Fig. 3). The highest abundance values were found at stations in group "e," followed in descending order by stations of groups "d," "c," "b," and "a."

SBI stations were divided into groups "a," "b," and "c" (Fig. 5). SBI group "a" included stations 066 and 116, which are located in the deep Filchner Trough. SBI group "b" included 4 stations $(033,040,098$, and 242) located in all three FROS sub-regions in water depths of 436-684 m. The remaining stations grouped in group "c," were distributed across the entire FROS region and a wide depth range of 254-1217 m. The SBI group " $\mathrm{c}$ " stations showed the highest mean abundances, group " $b$ " the lowest, and SBI group "a" contained just 2 stations with a max. abundance at st. 066 and a very low abundance at st. 116 (Fig. 4). SBI group "a" was dominated by holothurians, group " $b$ " by ophiuroids and, group "c" was dominated by ophiuroids and polychaetes (Fig. 4).

Despite the differences in MBC and SBI station groupings, a RELATE test showed that the among-station resemblance pattern in MBC data was significantly correlated with the pattern found in SBI (Spearman rank correlation; $\rho=0.395, p=0.01$ ). A first BEST test using MBC resemblances as "explanatory" matrix suggested that flatworms, priapulids, amphipods, cirripeds, and holothurians were the taxa "best explaining" the similarity pattern among SBI stations (Spearman rank correlation; $\rho=0.604$; $p=0.04)$. A vice versa BEST test with SBI resemblances as "explanatory" matrix showed brachiopods, pycnogonids, isopods, unidentified crustaceans, echinoids, asteroids, and ophiuroids to be the taxa "best explaining" the similarity pattern among MBC stations (Spearman rank correlation; $\rho=0.693 ; p=0.02)$.

\section{Discussion}

The total area covered by SBI during our study was two orders of magnitude larger than that covered by MBC samples. Rumohr (1995) described special features of different seabed imaging techniques; seabed still images cover a range of square centimeters up to square meters. Although seabed images cover larger areas of seafloor, this method is limited by the resolution of the images (Rumohr 1995). This 
Fig. 3 Mean abundance values (ind $\mathrm{m}^{-2}$ ) of dominant benthic taxa found in multibox corer samples collected during R/V Polarstern cruise PS82 (ANTXXIX/9) 2013/14. Dashed line represents the overall mean abundance

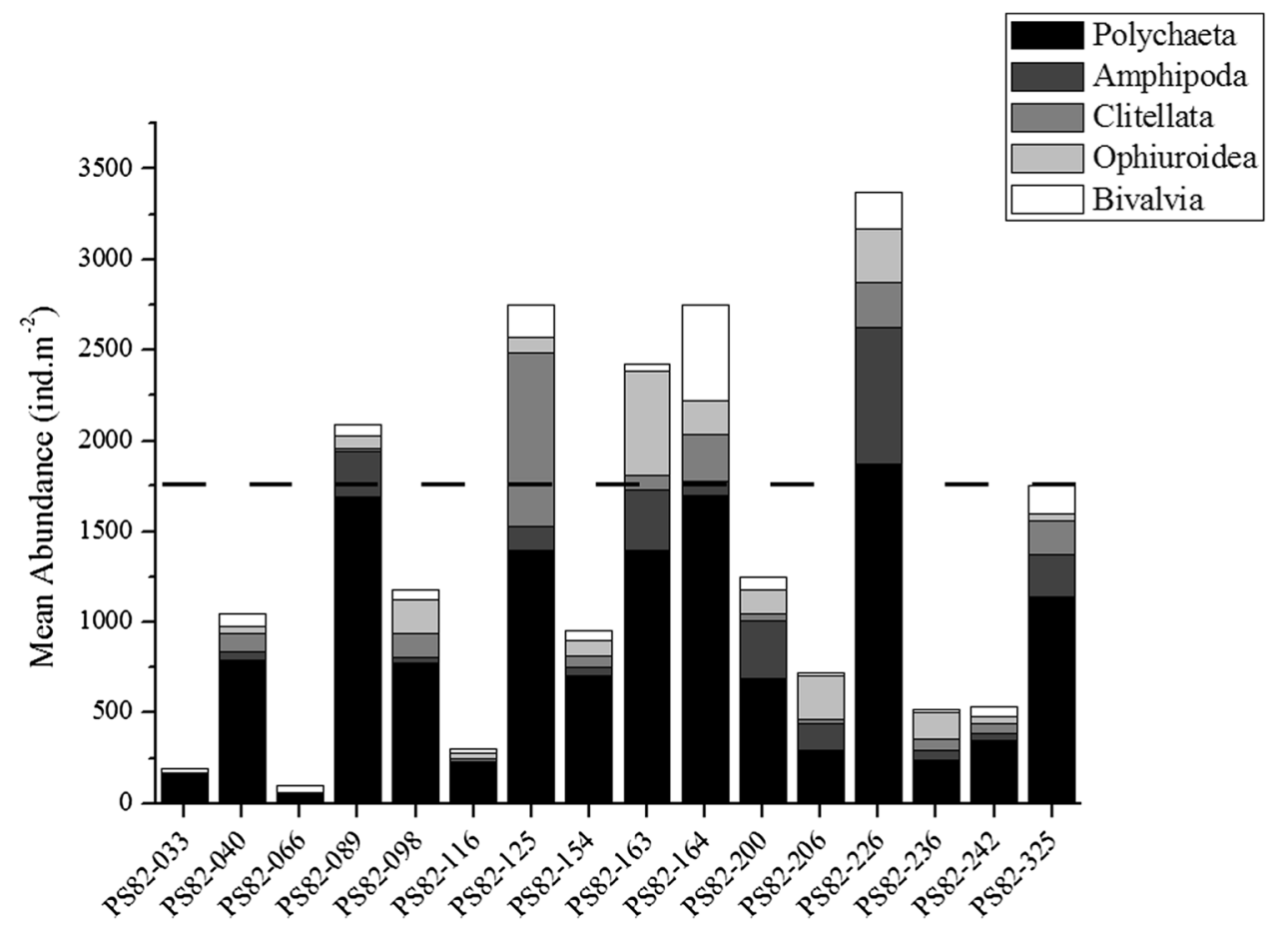

Fig. 4 Mean abundance values (ind $\mathrm{m}^{-2}$ ) of dominant benthic taxa identified in seabed images collected during R/V Polarstern cruise PS82 (ANT-XXIX/9) 2013/14. Dashed line represents the overall mean abundance

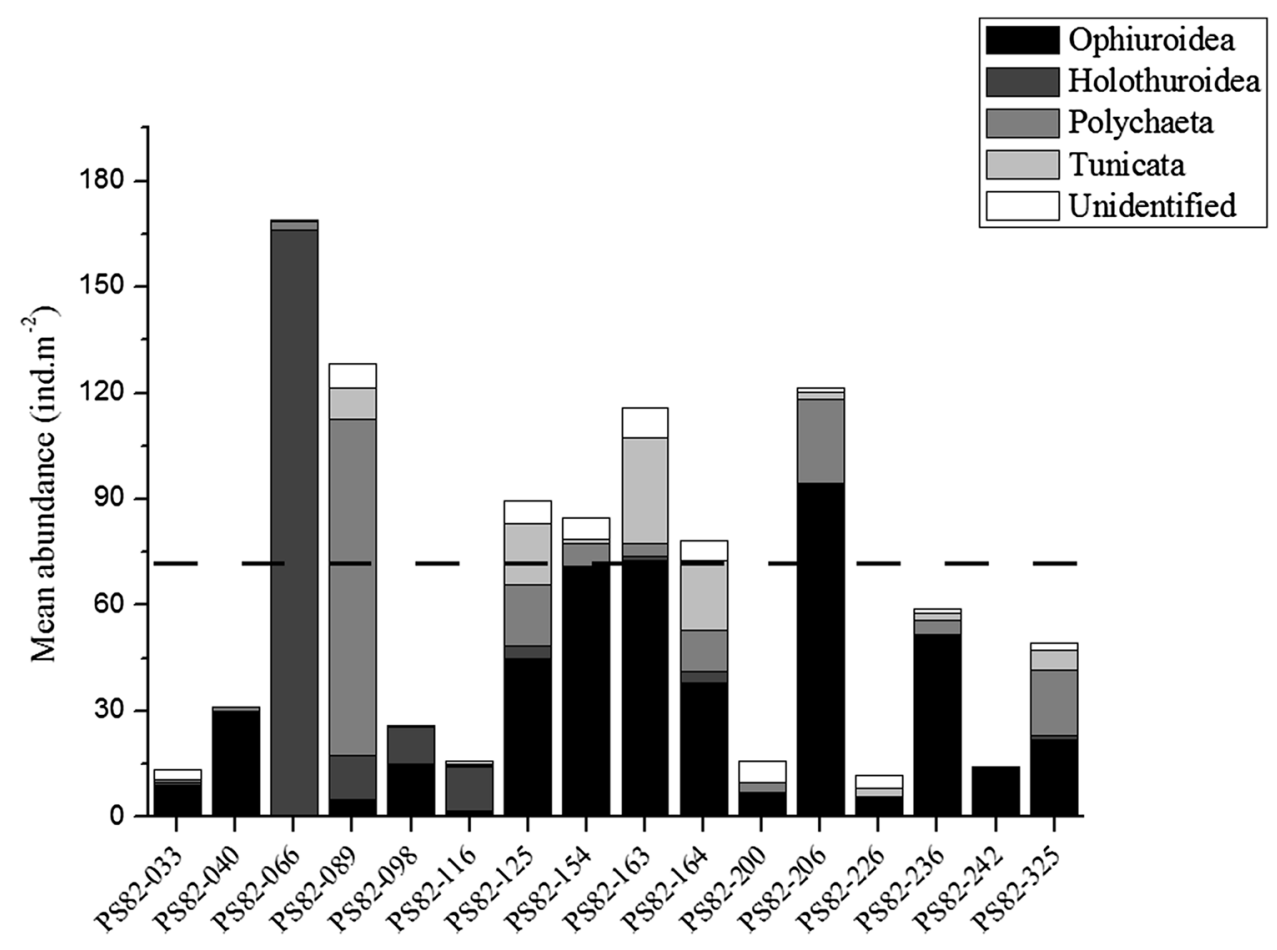

lack of high image resolution means that small organisms tend to be ignored and their importance for the community thus remains underestimated (Solan et al. 2003). Examples of such taxa are crustaceans, especially amphipods, tanaidaceans, small isopods, and ostracods, which occur regularly in high Antarctic shelf communities (Gerdes et al. 1992). On the other hand, the MBC with its small coring areas will underrepresent larger benthic organisms such as e.g., glass sponges. A way to overcome this problem is the use of giant box corers, which provide just one corer but of a larger area (0.25 m²; AWI 2006).

All data presented and discussed in this paper rely on organism numbers and neglect biomass estimates, because at the moment, we do not have the proxies to calculate 
Table 3 Results of two-way PERMANOVA test of significant differences in the structure of benthic assemblages investigated at 16 stations during RV Polarstern cruise PS82 (ANT-XXIX/9) 2013/14, with sampling gear-multibox corer samples (MBC) and seabed images (SBI) - as fixed factor and stations as random factor

\begin{tabular}{ll}
\hline Factor & PSEUDO-F \\
\hline Fixed: sampling gear (MBC, SBI) & $30.7^{*}$ \\
Random: station (16 levels) & $57.8^{*}$ \\
Factor interaction & $55.6^{*}$ \\
\hline
\end{tabular}

*Significant at $p<0.01$

Table 4 Results of SIMPER analysis of the composition of benthic fauna identified in multibox corer samples (MBC) and seabed images (SBI) taken at 16 stations during RV Polarstern cruise PS82 (ANTXXIX/9) 2013/14

\begin{tabular}{llc}
\hline Groups & MBC & SBI \\
\hline Average within-group & Overall: $54.29 \%$ & Overall: \\
similarity & Polychaeta: $37.83 \%$ & $66.17 \%$ \\
& Bivalvia: $11.47 \%$ & Ophi- \\
& Ophiuroidea: $11.05 \%$ & uroidea: \\
& & $35.24 \%$ \\
& & Polychaeta: \\
& & $14.72 \%$ \\
& & Holo- \\
& & thuroidea: \\
& & $9.96 \%$
\end{tabular}

Average between- $\quad$ MBC versus SBI group dissimilarity

\author{
Overall: $80.14 \%$ \\ Polychaeta: $17.52 \%$ \\ Ophiuroidea: $8.07 \%$ \\ Bivalvia: $7.78 \%$ \\ Amphipoda: $6.96 \%$ \\ Holothuroidea: $6.67 \%$ \\ Clitellata: $5.38 \%$
}

biomass from density and organism size measures from SBI. PERMANOVA results showed significant differences of abundance values between sampling methods across stations (Table 3). Mean abundance values obtained from MBC stations were orders of magnitude larger than those obtained from SBI, although the SBI recordings considered two orders of magnitude more sea floor area. The maximum abundance value derived from the images was 170 ind $\mathrm{m}^{-2}$, whereas comparable low abundance values in quantitative corer samples $\left(237,104\right.$, and 334 ind. $\left.\mathrm{m}^{-2}\right)$ were found only at three deep stations in the Filchner Trough (st. 033, 066, and 116 , respectively). The mean abundance per station derived from $\mathrm{MBC}$ samples $\left(1708\right.$ ind $\mathrm{m}^{-2}$ ) was more than 20 times higher than that obtained from SBI $\left(71\right.$ ind $\left.\mathrm{m}^{-2}\right)$.

There were distinct differences in the dominant taxa. Polychaetes were the most dominant taxon in the MBC samples, but ranked 3rd in SBI. In contrast, ophiuroids were the most dominant taxon in SBI, but ranked 4th in the MBC dominant taxa list (Fig. 2). With the exception of sedentary polychaetes, the dominant taxa in SBI include groups with medium mobility (e.g., ophiuroids and holothurians), organisms that are hard to capture with corers due to their size or patchy distribution (e.g., tunicates), and those that could not be identified. Unidentified organisms were found in 15 of the SBI stations and only at three MBC stations. The higher frequency of unidentified organisms found in SBI stations is not surprising when taking into account how organisms were identified. In SBI stations, organisms were identified directly from each image, which makes it difficult to distinguish small structures needed to properly identify individuals. Furthermore, in cases where images are out of focus or suspended particles are present, the task of identifying organisms is even harder. However, for MBC stations, organisms are identified in the laboratory by means of a stereomicroscope, making the identification task easier. MBC dominant taxa included organisms that either live in the substrate or are smaller than $1 \mathrm{~cm}$ in size. The SIMPER comparison between methods across stations showed a mix between SBI and MBC dominant taxa to be main contributors to differences between methods (Table 4).

Piepenburg et al. (2002) documented enormous differences in abundance and composition between quantitative data derived from MBC and SBI. These differences can be explained by the suitability of a gear for catching specific benthic components. As already mentioned in the "Introduction," corers are effective for collecting infaunal benthos, whereas seabed photography is better suited to map epifaunal benthos $>1 \mathrm{~cm}$ in size. Solan et al. (2003) explained the advantages of seabed images for observing epibenthic patterns pointing out that a fundamental problem remains, because a big part of the soft-bottom benthos is living burrowed in the sediment and can thus not be detected. In our study area, despite the presence of drop stones or gravel, the dominant sediment type at all stations was soft-sediment, which can be regarded as normal for the high Antarctic Weddell Sea shelf (Diekmann and Kuhn 1999b).

Combining both methods, we found a total of 43 taxa. Those taxa found exclusively in MBC samples include organisms living burrowed in the sediment or rather small organisms that are difficult to identify in images. Taxa exclusively found in SBI were either highly mobile, e.g., cephalopods and mysids, or they occurred in low abundances as e.g., nudibranchs (only one individual was found). A fact that stands out is the complementarity of the results obtained with both methods, i.e., taxa not or poorly represented in corer samples are better represented in images, and vice versa. This complementarity of both methods has been pointed out before (e.g., Rumohr 1995; Solan et al. 2003) and it is therefore surprising that both methods in combination are not used more often, since they can be treated as "the two sides of the same coin." 
Fig. 5 Two-dimensional MDS (multidimensional scaling) plots visualizing the among-station resemblance pattern of benthic fauna identified in a multibox corer samples (MBC) and b seabed images (SBI) collected during R/V Polarstern cruise PS82 (ANT-XXIX/9) 2013/14. The pattern is based on betweenstation Bray-Curtis similarities calculated from abundance (ind $\mathrm{m}^{-2}$ ) data. Grouping obtained from cluster and SIMPROF analysis is shown
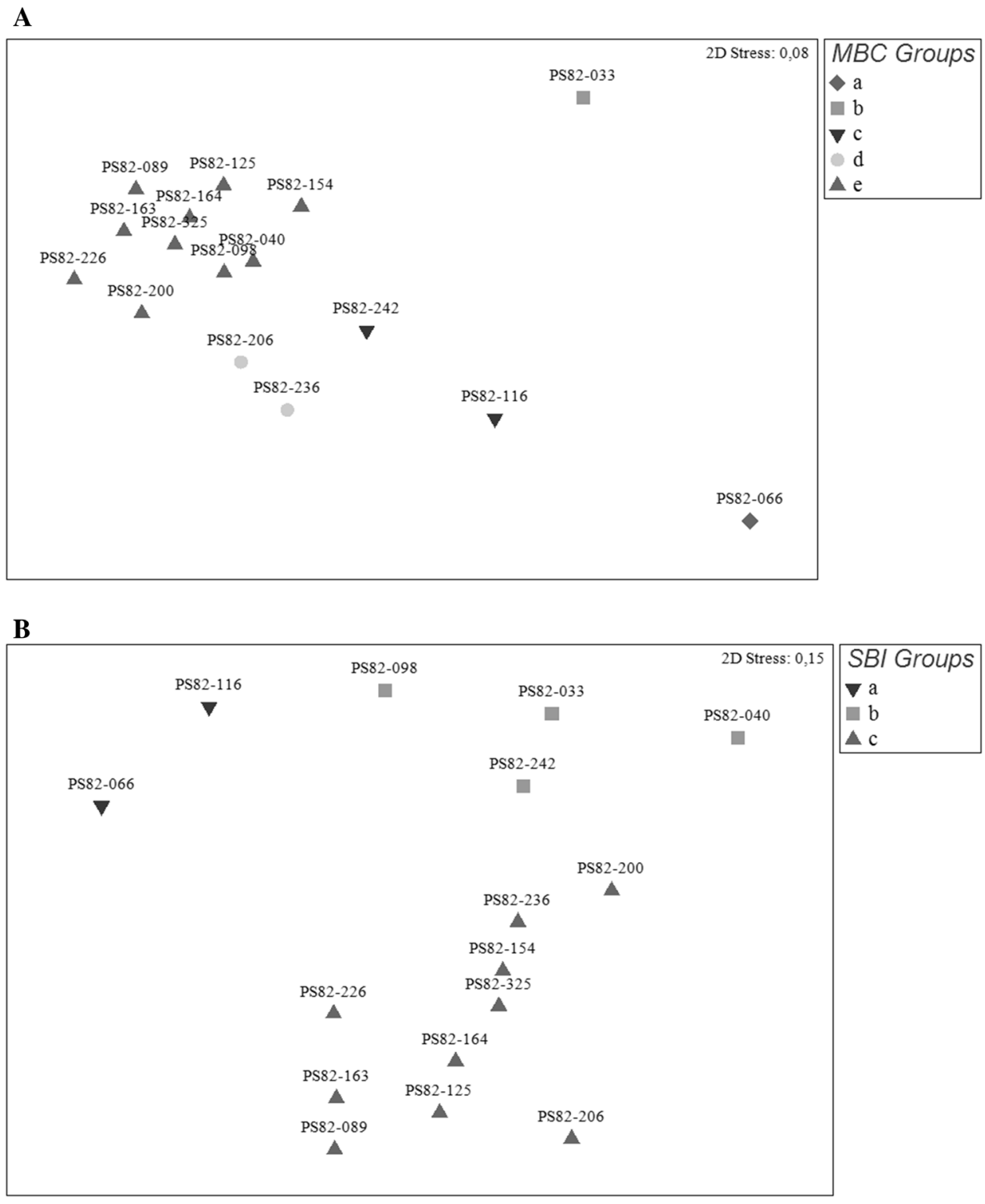

Table 5 Results of Principal Component Analysis (PCA) of the weighted abundances of benthic fauna identified in multibox corer samples (MBC) and seabed images (SBI) collected at 16 stations during R/V Polarstern cruise PS82 (ANT-XXIX/9) 2013/14

\begin{tabular}{llrll}
\hline $\begin{array}{l}\text { Sampling } \\
\text { gear }\end{array}$ & $\begin{array}{l}\text { Principal } \\
\text { compo- } \\
\text { nent }\end{array}$ & $\%$ variation & $\begin{array}{l}\text { Linear coef- } \\
\text { ficient }\end{array}$ & Taxa \\
\hline MBC & PC1 & 99.5 & -0.999 & Polychaeta \\
& PC2 & 0.2 & -0.776 & Clitellata \\
SBI & PC1 & 84.3 & -0.988 & Ophiuroidea \\
& PC2 & 12.4 & -0.988 & Holothuroidea \\
\hline
\end{tabular}

A combination of cluster, SIMPROF and MDS (Fig. 5) showed differences between station groups obtained from MBC and SBI data. Furthermore, the PCA results clearly showed that the driving factors for grouping were different, mainly polychaetes in the case of MBC, and the combination of ophiuroids and holothurians for SBI (Table 5; Figs. 6, 7). Despite these differences, the RELATE test showed that there is a statistically significant similarity between the distribution patterns of infaunal and epifaunal communities (Spearman rank correlation; $\rho=0.395 ; p<0.01$ ). This suggests a coupling between both benthic fractions. Such a match of distribution patterns resulting from both methods is a rather surprising result for two reasons: (a) our study region in the FROS is characterized by a heterogeneous topography inhabited by very different benthic community types (Voß 1988; Pineda-Metz et al. in prep). How infaunaland epifaunal benthos is affected by environmental gradients and how they respond to these gradients differs; thus, differences between benthic components are to be expected; and 


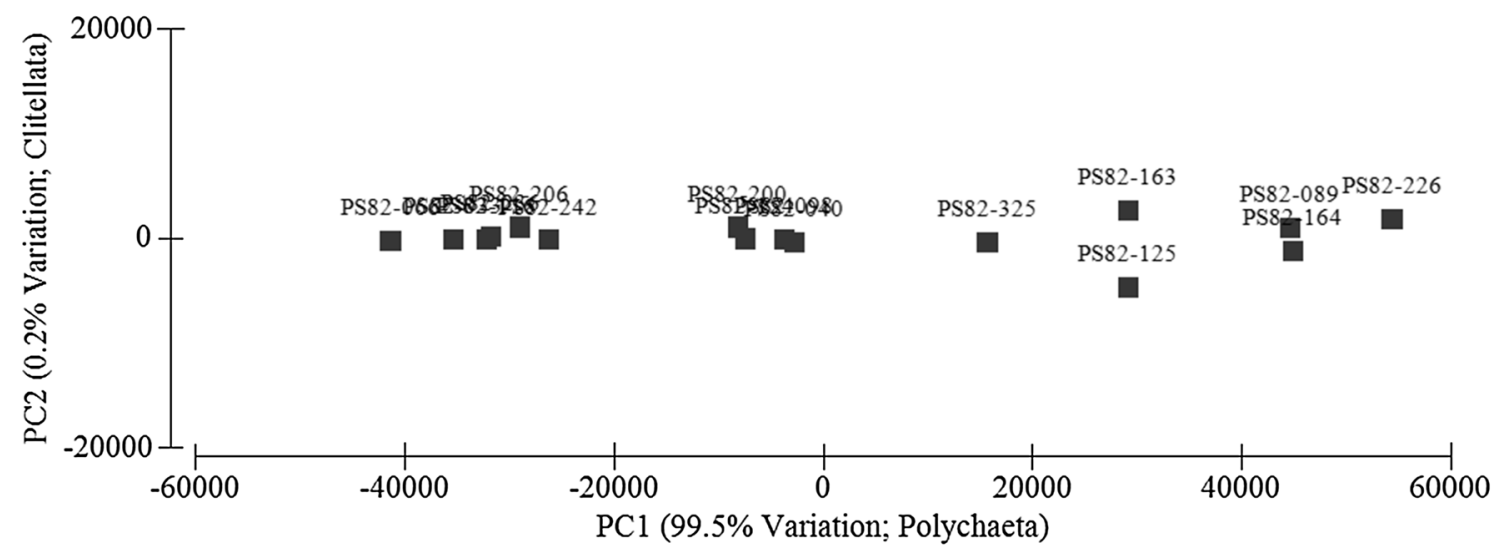

Fig. 6 Principal Component Analysis (PCA) of the weighted abundances of benthic taxa identified in multibox corer samples collected during R/V Polarstern cruise PS82 (ANT-XXIX/9) 2013/14. The first two axes (PC1 and PC2) explained 99.5 and $0.2 \%$, respectively, of the total variance

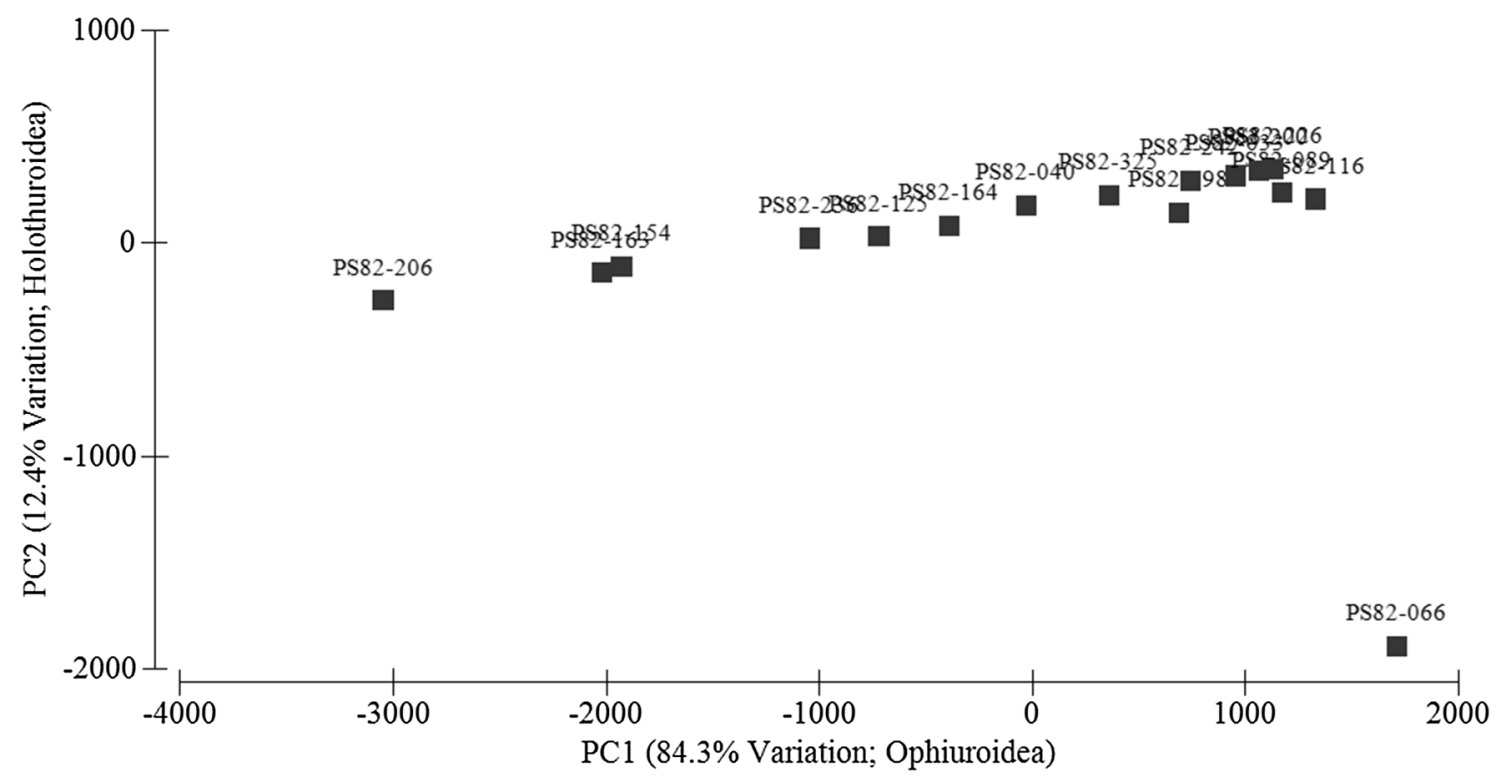

Fig. 7 Principal Component Analysis (PCA) of the weighted abundances of benthic taxa identified in seabed images collected during R/V Polarstern cruise PS82 (ANT-XXIX/9) 2013/14. The first two axes (PC1 and PC2) explained 84.3 and 12.4\%, respectively, of the total variance

(b) a similar approach (Piepenburg et al. 2002) of comparing benthic compartments with these two methods did not reveal such a match between distribution patterns of infaunal- and epifaunal benthos (RELATE test; $\rho=0.286 ; p=0.081$ ). Based on these facts and considering the methods to better describe either infaunal- or epifaunal benthic fractions, a mismatch between patterns would have been, a priori, a logical conclusion.

The match found with the RELATE test generated the question: which taxa might play a key role? In our study, we tried to answer this by comparing both MBC and SBI data by means of a BEST test. When using MBC data as an "explanatory" matrix for the pattern found in the SBIs, a combination of five taxa (flatworms, priapulids, amphipods, cirripeds, and holothurians) "best explains" the epifaunal pattern. Vice versa, when using SBI data as an "explanatory" matrix for the pattern found in MBC data, a combination of seven taxa (brachiopods, pycnogonids, isopods, unidentified crustaceans, echinoids, asteroids, and ophiuroids) "best explains" the infaunal benthos distribution pattern. The variables "best explaining" the patterns of infaunal- and epifaunal benthic distribution could be used to optimize mathematical models (e.g., linear multiple regression, maximum entropy models). 
Our study compares quantitative results from $\mathrm{MBC}$ and SBI samples. Although inherently different, they complement each other and future sampling strategies with deployment of both methods in parallel should be encouraged. Although traditional sampling with corers or towed gears resulted in robust descriptions of benthic communities with more focus on quantitative aspects (e.g., abundances/biomasses) or taxonomical composition, the combination of quantitative work with corers and seabed imaging methods increases the breadth of the community elements that can be described at each sampling site. Infaunal- and epifaunal benthos fractions and thus, the benthos as a whole can be described in more detail. Despite considering the benthic fractions in different resolution, both methods resulted in similar distribution patterns. Finally, it is worth mentioning that the combined use of both methods in the same gear, as the multibox corer in our study, is practicable, minimizing required ship time, and optimizing station grid and expedition planning.

Acknowledgements We would like to thank the crew of R/V Polarstern for their help and good disposition during the expedition PS82. Many thanks go also to Astrid Böhmer, Harald Biebow, and Chester Sands for giving a helping hand during station work onboard the ship, as well as to Claudio Richter, Dieter Piepenburg, Chester Sands, and three anonymous reviewers for their helpful contributions in polishing the content of this manuscript. Last but not least, we thank the persons who helped during the work on land in direct and indirect ways: Laura, Mario, Horacio, Lucas, Joaquín, Eric, Dario, and Renzo.

Open Access This article is distributed under the terms of the Creative Commons Attribution 4.0 International License (http://creativecommons.org/licenses/by/4.0/), which permits unrestricted use, distribution, and reproduction in any medium, provided you give appropriate credit to the original author(s) and the source, provide a link to the Creative Commons license, and indicate if changes were made.

\section{References}

Anderson MJ, Gorley RN, Clarke KR (2008) PERMANOVA+ for PRIMER: guide to software and statistical methods. PRIMER-E, Plymouth

Arndt JE, Schenke HW, Jakobsson M, Nitsche F, Buys G, Goleby B, Rebesco M, Bohoyo F, Hong JK, Black J, Greku R, Udintsev G, Barrios F, Reynoso-Peralta W, Morishita T, Wigley R (2013) The International Bathymetric Chart of the Southern Ocean (IBCSO) Version 1.0-a new bathymetric compilation covering circumAntarctic water. Geophys Res Lett 40:3111-3117. doi:10.1002/ grl.50413

AWI (2006) Box Corer (engineering detail drawing of the large version). Alfred Wegener Institute, Helmholtz Center for Polar and Marine Research, Bremerhaven. doi:10.1594/PANGAEA.510788

Blomqvist S (1991) Quantitative sampling of soft-bottom sediments: problems and solutions. Mar Ecol Prog Ser 72:295-304

Bray JR, Curtis JT (1957) An ordination of upland forest communities of southern Wisconsin. Ecol Monogr 27:325-349

Clark MR, Consalvey M, Rowden AA (2016) Biological sampling in the deep sea. Wiley-Blackwell, New Jersey
Clarke A (2008) Antarctic marine benthic diversity: patterns and processes. J Exp Mar Biol Ecol 366:48-55

Clarke KR, Gorley RN (2006) PRIMER 6: user manual/tutorial. PRIMER-E, Plymouth

Clarke KR, Warwick RM (1994) Change in marine communities. Natural Environmental Research Council, Plymouth

Clarke KR, Somerfield PJ, Gorley RN (2008) Testing null hypotheses in exploratory community analyses: similarity profiles and biotaenvironment linkage. J Exp Mar Biol Ecol 320:11-27

Dauvin J-C, Vallet C (2006) The near-bottom layer as an ecological boundary in marine ecosystems: diversity, taxonomic composition and community definitions. Hydrobiologia 555:49-58. doi:10.1007/s10750-005-1105-5

Diekmann B, Kuhn G (1999a) Grain size distribution of surface sediments in the South Atlantic. PANGAEA. doi:10.1594/ PANGAEA.54633

Diekmann B, Kuhn G (1999b) Provenance and dispersal of glacialmarine surface sediments in the Weddell Sea and adjoining areas, Antarctica: ice-rafting versus current transport. Mar Geol 58:209_ 231. doi:10.1016/S0025-3227(98)00165-0

Eleftheriou A, McIntyre AD (2005) Methods for the study of marine benthos. Blackwell Publishing Company, Oxford

Fillinger L, Janussen D, Lundälv T, Richter C (2013) Rapid glass sponge expansion after climate-induced Antarctic ice shelf collapse. Curr Biol 23:1330-1334

Gerdes D (1990) Antarctic trials of the multibox corer, a new device for benthos sampling. Polar Rec 26:35-38

Gerdes D, Klages M, Arntz WE, Herman RL, Galéron J, Hain S (1992) Quantitative investigations on macrobenthos communities of the southeastern Weddell Sea shelf based on multibox corer samples. Polar Biol 12:291-301

Gerdes D, Hilbig B, Montil A (2003) Impact of iceberg scouring on macrobenthic communities in the high-Antarctic Weddell Sea. Polar Biol 26:295-301. doi:10.1007/s00300-003-0484-1

Gerdes D, Isla E, Knust R, Mintenbeck K, Rossi S (2008) Response of Antarctic benthic communities to disturbance: first results from the artificial Benthic Disturbance Experiment on the eastern Weddell Sea Shelf. Pol Biol, Antarctica. doi:10.1007/ s00300-008-0488-y

Gutt J, Piepenburg D (2003) Scale-dependent impact on diversity of Antarctic benthos caused by grounding of icebergs. Mar Ecol Prog Ser 253:77-83

Gutt J, Barrat I, Domack E, d'Udekem d'Acoz C, Dimmler W, Grémare A, Heilmayer O, Isla E, Janussen D, Jorgensen E, Kock K-H, Lehner LS, López-Gonzáles P, Langner S, Linse K, Manjón-Cabeza ME, Meißner M, Montiel A, Raes M, Robert H, Rose A, Sañé Schepisi E, Saucède T, Scheidat M, Schenke H-W, Seiler J, Smith C (2011) Biodiversity change after climate-induced ice-shelf collapse in the Antarctic. Deep-Sea Res II 58:74-83

Gutt J, Cape M, Dimmler W, Fillinger L, Isla E, Lieb V, Lundälv T, Pulcher C (2013) Shifts in Antarctic megabenthic structure after iceshelf disintegration in the Larsen area east of the Antarctic Peninsula. Polar Biol 36:895-906. doi:10.1007/s00300-013-1315-7

Knust R, Schröder M (2014) The expedition PS82 of the research vessel Polarstern to the southern Weddell Sea in 2013/2014. Ber Polarforsch Meeresforsch 680:1-155. doi:10.2312/BzPM_680_2014

Lozach S, Dauvin J-C, Méar Y, Murat A, Davoult D, Migné A (2011) Sampling epifauna, a necessity for a better assessment of benthic ecosystem functioning: an example of benthic epibenthic aggregated species Ophiothrix fragilis from the Bay of Seine. Mar Pollut Bull 62:2753-2760

Mantel N (1967) The detection of disease clustering and a generalized regression approach. Cancer Res 27:209-220

Piepenburg D, Juterzenka KV (1994) Abundance, biomass and spatial distribution pattern of brittle stars (Echinodermata: Ophiuroidea) on the Kolbeinsey Ridge north of Iceland. Polar Biol 14:185-194 
Piepenburg D, Schmid MK, Gerdes D (2002) The benthos off King George Island (South Shetland Islands, Antarctica): further evidence for a lack of a latitudinal biomass cline in the Southern Ocean. Polar Biol 35:146-158. doi:10.1007/s003000100322

Rumohr H (1995) Monitoring the marine environment with imaging methods. Sci Mar 59(1):129-138

Sañé E, Isla E, Gerdes D, Montiel A, Gili G-M (2012) Benthic macrofauna assemblages and biochemical properties of sediments in two Antarctic regions differently affected by climate change. Cont Shelf Res 35:53-63

Schröder M, Wisotzki A (2014) Physical oceanography measured on water bottle samples during POLARSTERN cruise PS82 (ANTXXIX/9). Alfred Wegener Institute, Helmholtz Center for Polar and Marine Research, Bremerhaven, PANGAEA. doi:10.1594/ PANGAEA.833299
Solan M, Germano JD, Rhoads DC, Smith C, Michaud E, Parry D, Wenzhöfer F, Kennedy B, Henriuqes C, Battle E, Carey D, Iocco L, Valente R, Watson J, Rosenberg R (2003) Towards a greater understanding of pattern, scale and precess in marine benthic systems: a picture is worth a thousand worms. J Exp Mar Biol Ecol 285-286:313-338

Syvitski JPM, Farrow GE, Atkinson RJA, Moore PG, Andrews JT (1989) Baffin Island fjord macrobenthos: bottom communities and environmental significance. Arctic 42:242-247

Thurston MH, Bett BJ, Rice AL, Jackson PAB (1994) Variations in the invertebrate abyssal megafauna in the North Atlantic Ocean. Deep Sea Res 41:1321-1348

Voß J (1988) Zoogeographie und Gemeinschaftsanalyse des Makrozoobenthos des Weddellmeeres (Antarktis). Ber Polarforsch 45:1-145 